\title{
KNOWLEDGE, ATTITUDE AND PRACTICES OF HAND HYGIENE AMONG MBBS STUDENTS AND NURSING PERSONNEL
}

\author{
Pooja Sarmah', Hemavathi², Sharvani Rajashekar ${ }^{3}$, Poornima Shenoy ${ }^{4}$
}

Associate Professor, Department of Microbiology, Sapthagiri Institute of Medical Sciences \& Research Center, Bangalore. Professor \& HOD, Department of Microbiology, Sapthagiri Institute of Medical Sciences \& Research Center, Bangalore. Assistant Professor, Department of Microbiology, Sapthagiri Institute of Medical Sciences \& Research Center, Bangalore. Professor, Department of Microbiology, Sapthagiri Institute of Medical Sciences \& Research Center, Bangalore.

\section{ABSTRACT}

\section{BACKGROUND}

Hospital-acquired infections are important cause for morbidity, mortality, and increased costs among patients. Hand hygiene plays an important role in prevention of hospital-acquired infections. However, compliance to hand hygiene is very poor. The knowledge, attitude and practices to hand hygiene may vary among different groups of hospital personnel like nurses, doctors and students.

\section{MATERIALS AND METHODS}

Fifty final year MBBS students and 50 nurses were selected voluntarily and were asked to fill a self-administered questionnaire on hand hygiene. The questionnaire had five parts i.e., demographic information, questions on knowledge, attitude, practices and satisfaction with availability of resources to hand hygiene. The results were statistically analysed using the independent sample-t test and the p-value of less than 0.05 was considered.

\section{RESULTS}

The knowledge, attitude and practices were poor among MBBS students as compared to the nursing staff. Conclusion: There is an urgent need to reinforce the importance of hand hygiene practices among medical students in each year of their MBBS curriculum.

\section{KEYWORDS}

Attitude, Hand Hygiene, Knowledge, Medical Students, Nurses, Practice.

HOW TO CITE THIS ARTICLE: Sarmah P, Hemavathi, Rajashekar S, et al. Knowledge, attitude and practices of hand hygiene among MBBS students and nursing personnel. J. Evolution Med. Dent. Sci. 2016;5(36):2083-2086, DOI: 10.14260/jemds/2016/489

\section{INTRODUCTION}

Hands play an important part in infection transmission in a health care setting. ${ }^{1}$

Hands of health care workers carry resident and transient bacterial flora. The transient flora includes bacteria like coagulase negative Staphylococci, diphtheroids, etc. which are not usually harmful but may be important in immunocompromised patients. However, it is the transient bacterial flora which is the main culprit in causing hospitalacquired infections (HAI). They get carried on to the hands of the health care workers from the patient or the patient's environment. ${ }^{2}$ These transient flora can be easily removed by hand hygiene techniques as compared to the resident bacterial flora. Various HAIs like surgical-site infections, ventilator-associated pneumonias, blood-stream infections caused by various pathogens can be prevented by proper adherence to hand hygiene. ${ }^{3}$

The World Health Organization provides clear guidelines on the techniques of hand hygiene. Poor adherence to hand hygiene practices are responsible for $40 \%$ of these infections. ${ }^{4}$

Financial or Other, Competing Interest: None.

Submission 21-03-2016, Peer Review 15-04-2016,

Acceptance 21-04-2016, Published 03-05-2016.

Corresponding Author:

Dr. Pooja Sarmah,

Associate Professor

Department of Microbiology,

Sapthagiri Institute of Medical Sciences \& Research Center,

Hesaraghatta Road,

Bangalore.

E-mail: drpoojasarmah@gmail.com

DOI: $10.14260 /$ jemds/2016/489
The foundation stone for hand hygiene practices were laid in the year 1847 by Sir Ignaz Philipp Semmelweis which holds good even now. Following the introduction of hand hygiene in the hospital where Sir Semmelweis was working, the maternal mortality rate had reduced to $3.06 \%$ proving the effectiveness of hand hygiene. Hence, he is considered as the father of hand disinfection and hospital epidemiology. 5

Even though it is a simple and effective procedure, it is many times ignored by the health care workers due of lack of knowledge, interest, time constraints, skin irritation, understaffing, etc. ${ }^{5}$ Under hand hygiene techniques, there are hand washing i.e. washing hands with regular soap and water, hygienic hand wash i.e. washing hands with medicated soap and water and hygienic hand-rub i.e. use of antiseptic hand rubs which are usually alcohol based. 6 All are effective methods when followed according to correct technique and for adequate amount of time.

As mentioned before, adherence to hand hygiene is poor, and as low as $50 \%$ compliance is observed in some areas. ${ }^{7}$ Knowledge and compliance to hand hygiene practices vary among various health care workers like students, nurses, doctors and other professionals. It is especially poor among medical students and doctors. ${ }^{8}$

To bring about positive change in hand hygiene behaviour, it is first important to understand the hurdles leading to poor compliance. Is it the lack of knowledge, improper attitude or non-availability of infrastructure which is the reason for poor compliance? It is also imperative to know what practices are followed so as to bring about change if needed. Hence, this study was conducted to understand and compare the knowledge, attitude and practices related to 
hand hygiene among nursing staff and final year medical students.

\section{OBJECTIVE OF THE STUDY}

The objective of the present study was to compare the knowledge, attitude and practices in hand hygiene among nursing staff and final year MBBS students.

\section{MATERIALS AND METHODS:}

The study was conducted in the year 2015-16 in a medical college of South India. It was a questionnaire based crosssectional study. A standard self-administered questionnaire was prepared and handed over to fifty final year MBBS students and fifty nursing staff. The participants were briefly instructed on how to go about filling the form. Informed consent was taken and the volunteers were instructed to fill the demographic information and tick the correct option for questions on knowledge, attitude, practices and availability of hand hygiene facilities. The questionnaire had five parts. First section included demographic data. The second section assessed the knowledge regarding hand hygiene by giving them ten multiple choice questions based on the WHO questionnaire. ${ }^{9}$ In the third section, attitude was assessed by using nine questions with Likert-type grading with options ranging from strongly agreed, agreed, neutral, disagree and strongly disagree. The fourth section was to assess practices of hand hygiene by seven questions (yes or no), and the fifth section included five questions of yes or no type on the facilities available.

Ethical clearance was taken from the Institutional Ethical Committee. The results of the knowledge, attitude and practices of hand hygiene between the medical students and the nursing staff were compared statistically using independent sample-t test. The bio-statistical data was analysed using SPSS software v 20.0.

\section{RESULTS}

The questionnaire was filled by 50 nursing staff and 50 final year MBBS students. Among the nursing staff, the working experience ranged from three months to 10 years. Among the students, there were 17 (34\%) males and 33 (66\%) females. Among the nursing staff, there were eight males $(16 \%)$ and $42(84 \%)$ females.
The overall knowledge of the nursing staff was better as compared to the medical students as shown in Table 1 and this difference was significant with $\mathrm{p}$-value of 0.0034 . When they were questioned about the source of infection and route of infection, more than $50 \%$ of nursing staff answered correctly as compared to the medical students. Sixty-eight percent of the nursing staff could answer about the correct time needed for alcoholic hand rub and $50 \%$ of the medical students could answer correctly. However, $58 \%$ of nurses and $44 \%$ of students answered that hand rub causes more dryness than hand wash.

The attitudes of both the groups were compared and the nursing staff had better attitude than the medical students (Table 2). Most of the nursing staff and medical students agreed or strongly agreed that they comply to hand hygiene practices. However, most of the students agreed or strongly agreed that their knowledge was poor, but the nursing staff appeared confident with their knowledge on hand hygiene. Nursing staff also disagreed that other things came up during patient care like emergencies which were more important than hand hygiene. When asked if they felt frustrated when others or they themselves omitted hand hygiene, majority of the nursing staff agreed and strongly agreed that they were guilty as compared to the students. Majority of the nursing staff agreed or strongly agreed to wash hands before aseptic procedures and follow the correct time and also trained the newcomers. This trend was not seen much with the medical students.

The hand hygiene practice of the nursing staff was slightly better as compared to the students as both of the groups gave similar responses. However, this difference was not significant, $p$ value 0.89 (Table 3 ).

The nursing staff were more satisfied as compared to the students with the availability of resources for hand hygiene and this difference was found to be statistically significant $p$ value 0.0001 (Table 4). Majority of the nursing staff were satisfied with the availability of various disinfectants and other items related to hand hygiene like gloves, liquid soap, etc. They were also satisfied with the infrastructure provided like sinks and water supply and also the various training programs conducted by the infection control team. This did not reflect the same way with the students.

\begin{tabular}{|c|c|c|c|c|}
\hline & & $\begin{array}{c}\text { No. and Percentage of } \\
\text { Students with Correct } \\
\text { Answer (\%) }\end{array}$ & $\begin{array}{l}\text { No. and Percentage of Nursing } \\
\text { Staff with Correct Answer (\%) }\end{array}$ & $P$ value \\
\hline K1 & $\begin{array}{l}\text { Which of the following is the most } \\
\text { important route of transmission of } \\
\text { potentially harmful germs between } \\
\text { patients }\end{array}$ & $21(42 \%)$ & $32(64 \%)$ & 0.009 \\
\hline $\mathrm{K} 2$ & $\begin{array}{l}\text { What is the most important source of } \\
\text { germs for hospital-acquired infection }\end{array}$ & $5(10 \%)$ & $11(22 \%)$ & 0.02 \\
\hline K3 & $\begin{array}{l}\text { Which must be avoided to prevent } \\
\text { colonisation with germs }\end{array}$ & $3(6 \%)$ & $21(42 \%)$ & 0.87 \\
\hline K4 & $\begin{array}{l}\text { Hand rubbing causes more dryness than } \\
\text { hand wash }\end{array}$ & $22(44 \%)$ & $29(58 \%)$ & 0.49 \\
\hline K5 & $\begin{array}{l}\text { Hand washing and hand rubbing should } \\
\text { be performed in sequence }\end{array}$ & $18(36 \%)$ & $12(24 \%)$ & 0.43 \\
\hline K6 & $\begin{array}{l}\text { What time is required by alcoholic hand } \\
\text { rub to kill germs }\end{array}$ & $25(50 \%)$ & $34(68 \%)$ & 0.53 \\
\hline
\end{tabular}




\begin{tabular}{|c|c|c|c|c|}
\hline & \multicolumn{2}{|c|}{ What type of hand hygiene should be followed before the following procedures } & $26(52 \%)$ & 0.50 \\
\hline K7 & After touching patients & $22(44 \%)$ & $41(82 \%)$ & 0.38 \\
\hline K8 & $\begin{array}{c}\text { Immediately after risk of body fluid } \\
\text { exposure }\end{array}$ & $45(90 \%)$ & $36(72 \%)$ & 0.45 \\
\hline K9 & $\begin{array}{c}\text { Immediately before a clean or aseptic } \\
\text { procedure }\end{array}$ & $32(64 \%)$ & $20(40 \%)$ & 0.54 \\
\hline K10 & $\begin{array}{c}\text { After exposure to immediate } \\
\text { surroundings of patients }\end{array}$ & $23(46 \%)$ & 20 Table 1: Comparison of Knowledge in Hand Hygiene among Nursing Staff and MBBS Students \\
\hline \multicolumn{2}{|c|}{}
\end{tabular}

Table 1: Comparison of Knowledge in Hand Hygiene among Nursing Staff and MBBS Students

\begin{tabular}{|c|c|c|c|c|c|c|c|c|c|c|c|}
\hline & & \multicolumn{5}{|c|}{ Nurses } & \multicolumn{5}{|c|}{ Students } \\
\hline & & SA $^{*}$ & $\mathbf{A} \dagger$ & $\mathbf{N} \neq$ & $\mathbf{D} \S$ & SD $\|$ & $\mathbf{S A}^{*}$ & $\mathbf{A} \dagger$ & $\mathbf{N} \neq$ & $\mathbf{D} \S$ & $\mathbf{S D} \|$ \\
\hline A1 & I adhere to hand hygiene practices at all times & 36 & 13 & 0 & 1 & 0 & 24 & 25 & 1 & 0 & 0 \\
\hline A2 & $\begin{array}{l}\text { I have sufficient knowledge about hand } \\
\text { hygiene }\end{array}$ & 34 & 10 & 2 & 4 & 0 & 10 & 11 & 0 & 20 & 9 \\
\hline A3 & $\begin{array}{l}\text { I sometimes have more important things to } \\
\text { do than hand hygiene }\end{array}$ & 16 & 9 & 2 & 21 & 2 & 5 & 2 & 7 & 21 & 15 \\
\hline A4 & $\begin{array}{l}\text { Wearing gloves reduce the need for hand } \\
\text { hygiene }\end{array}$ & 11 & 16 & 2 & 16 & 5 & 6 & 9 & 12 & 19 & 4 \\
\hline A5 & $\begin{array}{l}\text { I feel frustrated when others omit hand } \\
\text { hygiene }\end{array}$ & 15 & 12 & 10 & 10 & 3 & 6 & 8 & 10 & 11 & 15 \\
\hline A6 & I feel guilty when I omit hand hygiene & 28 & 6 & 2 & 10 & 4 & 10 & 8 & 22 & 1 & 9 \\
\hline A7 & $\begin{array}{l}\text { I wash my hand before \& after aseptic } \\
\text { procedures }\end{array}$ & 42 & 6 & 2 & 0 & 0 & 10 & 22 & 13 & 4 & 1 \\
\hline A8 & $\begin{array}{l}\text { I always follow the correct time for hand } \\
\text { wash \& hand rub }\end{array}$ & 38 & 9 & 2 & 1 & 0 & 10 & 9 & 24 & 3 & 4 \\
\hline A9 & I train the new comers & 36 & 11 & 2 & 1 & 0 & 5 & 2 & 12 & 3 & 28 \\
\hline
\end{tabular}

*Strongly agree † Agree ‡ Neutral, §Disagree, || Strongly Disagree.

\begin{tabular}{|c|c|c|c|c|}
\hline & & Nurses & Students & P value \\
\hline P1 & Adhering to hand hygiene practices are easy & $44(88 \%)$ & $38(76 \%)$ & 0.279 \\
\hline $\mathrm{P} 2$ & Emergencies make hand hygiene more difficult at times & $38(76 \%)$ & $42(84 \%)$ & 0.223 \\
\hline P3 & Sometimes I miss out hand hygiene because I forget & $15(30 \%)$ & $25(50 \%)$ & 0.025 \\
\hline $\mathrm{P} 4$ & Hand hygiene is an essential part of our role- & $48(96 \%)$ & $49(98 \%)$ & 0.562 \\
\hline $\mathrm{P} 5$ & The frequency of hand wash required makes it difficult for me to follow- & $17(34 \%)$ & $22(44 \%)$ & 0.310 \\
\hline P6 & Infection control team has a positive influence on my hand hygiene & $47(94 \%)$ & $35(70 \%)$ & 0.001 \\
\hline P7 & It is difficult for me to attend to hand hygiene due to work pressure & $17(34 \%)$ & $13(26 \%)$ & 0.38 \\
\hline
\end{tabular}

\begin{tabular}{|c|c|c|c|}
\hline & Nursing & \multicolumn{2}{c|}{ Students } \\
\hline Are you satisfied with the facilities for following hand hygiene? Availability of \\
\hline Alcoholic hand rubs & $49(99 \%)$ & $42(84 \%)$ & 0.001 \\
\hline Gloves & $50(100 \%)$ & $30(60 \%)$ & 0.0001 \\
\hline Number of washbasins with running water & $50(100 \%)$ & $24(48 \%)$ & 0.0001 \\
\hline Soap- liquid or solid bars- & $46(92 \%)$ & $23(46 \%)$ & 0.0001 \\
\hline Training programs on hand hygiene conducted by the Infection control team & $50(100 \%)$ & $33(66 \%)$ & 0.0001 \\
\hline Table 4: Satisfaction among the Nursing Staff and MBBS Students to the Facilities Available \\
\hline
\end{tabular}

\section{DISCUSSION}

Hand hygiene prevents hospital-acquired infections. This basic, simple yet effective procedure is many times ignored. As mentioned before, knowledge and compliance may be poor in various groups of people who work in the hospital. Hence, to understand this kind of behaviour among nursing staff and medical students, this study was conducted.

In our study, we found that the nursing staff had better knowledge as compared to the medical students. The reason for this, we perceive, must be that regular classes and training programs which are conducted periodically for nursing personnel of our hospital as a part of infection control program; however, medical students are not exposed to hand hygiene before the second year as a part of Microbiology subject or, during clinical postings, when they may see the hand hygiene posters displayed in the wards and the outpatient departments. There are no separate classes conducted on infection control or hand hygiene to the students of other years as it is not present in the curriculum. Hence, there is lack of reinforcement.

When the attitude was compared it was also seen that the nursing staff had better attitude as compared to the medical students. This poor attitude among medical students is very disappointing. This poor attitude may be attributed to the fact that undergraduate students are not directly involved in patient care as they do not personally follow up cases. Hence, they do not see the consequences of infection control directly. However, correct attitude must be instilled right from undergraduate level to bring about required change. 
On comparing the practices among both the groups, it was found that practice of hand hygiene was also slightly better among the nursing staff as compared to the medical students. This may be due to the fact that during clinics, the nursing staff and the doctors insist on the students to follow these hand hygiene practices which the majority of the students do without really linking its applications to their second year MBBS class knowledge. This paucity of knowledge and attitude among medical students is similar to a study conducted by Feather $\mathrm{A}$ et al and Hunt D.C.E et al.10,11A study conducted by Madhavi et al, however, shows good compliance to hand hygiene among house surgeons. ${ }^{12}$ In a study conducted by Ariyartane MHJD et al, the knowledge among medical students was poor as compared to nursing students. 13

The nursing staff was satisfied with the availability of all the items and infrastructure needed for hand hygiene including the hand hygiene or infection control classes as compared to the medical students since there is a paucity of training programmes for students. Hence, such dissatisfaction with the available resources among them can be expected. This may be encouraging as this shows the willingness on the part of the students to learn.

All of this emphasises on the need of involving the medical students more into infection control programs with emphasis on practices like hand hygiene by conducting continued classes to bridge the gap of knowledge, attitude and practices. Training sessions, continued medical education, display of posters at appropriate areas, reinforcement of hand hygiene techniques by demonstration or objective structured clinical examination stations (OSCE) and feedbacks may need to be introduced at undergraduate level at the different terms especially during clinical postings to keep the students motivated and informed about current practices on hand hygiene.

\section{CONCLUSION}

There is a need to make the medical students to be more aware about hand hygiene and its practices. A simple step of following the correct technique goes a long way in preventing hospital-acquired infections. Hence, having more teaching hours on hand hygiene in all the years of MBBS curriculum must be thought of to improve their knowledge and to motivate the students to inculcate correct attitude and behaviour, as the healthcare of the future lies on their shoulders.

\section{ACKNOWLEDGEMENT}

I would like to thank Mrs. Lavanya, Statistician, Sapthagiri Institute of Medical Sciences and Research Centre, Bangalore90 for the statistical help.

\section{REFERENCES}

1. Aiello AE, Larson EL. What is the evidence for a causal link between hygiene and infections? Lancet Infect Dis 2002;2(2):103-10.

2. www.ijdr.in Hand hygiene among health care workers.

3. US department of health and human service, agency for healthcare research and quality, primers, patient safety primers.

https://psnet.ahrq.gov/primers/primer/7/health-careassociated-infections.

4. Inweregbu K, Dave J, Pittard A. Nosocomial infections. continuing education in anesthesia. Critical Care \& Pain 2005;5(1):14-7.

5. Pittet D, Boyce JM. Hand hygiene and patient care: pursuing the Semmelweis legacy. The Lancet Infectious Diseases 2001;1:9-20.

6. Wendt C. Hand hygiene-comparison of international recommendations. J Hosp Infect 2001;48(suppl A):S238.

7. Pittet D. Improving adherence to hand hygiene practice: a multidisciplinary approach. Emerging Infectious Diseases 2001;7(2):234-40.

8. El Aziz KMA, Bakr IM. Assessment of knowledge, attitude and practice of hand washing among health care workers in ain shams university hospitals in Cairo. Prev Med Hyg 2009;50(1):19-25.

9. Hand hygiene knowledge questionnaire for health care workers. [Internet] [Place unknown] [WHO] Revised August 2009. Available from: http://www.who.int/gpsc/5may/tools/evaluation_feed back/en/

10. Feather A, Stone SP, Wessier A, et al. Now please wash your hands: the hand washing behaviour of final MBBS candidates. Journal of Hospital Infection 2000;45(1):62-4.

11. Hunt DCE, Mohammudaly A, Stone SP, et al. Handhygiene behaviour, attitudes and beliefs in first year clinical medical students. Journal of Hospital Infection 2005;59(4):371-3.

12. Madhavi P, Prakash KK. Awareness of hand washing among house-surgeons of government general hospital, Vijayawada. Journal of Evolution of Medical and Dental Sciences 2014;3(14):3609-13.

13. Ariyaratne MHJD, Gunasekara TDCP, Weerasekara MM, et al. Knowledge, attitudes and practices of hand hygiene among final year medical and nursing students at the university of sri Jayewardenepura. Sri Lankan Journal of Infectious Diseases 2013;3(1):15-25. 